\title{
A Comparison of Minkowski, Compact Multiband and Microstrip Fractals with Meander Fractal Antenna
}

\author{
Jaspreet Singh \\ M.Tech Scholar \\ Electronics and Communication \\ Engineering Deptt. \\ Amritsar College of \\ Engineering and Technology, \\ Amritsar
}

\author{
Narinder Sharma \\ Associate Professor \\ Electronics and Communication \\ Engineering Deptt. \\ Amritsar College of Engineering \\ and Technology, \\ Amritsar
}

\begin{abstract}
This paper presents the comparison of existing fractal antennas with the proposed fractal antenna on the basis of performance parameters such as return loss and gain. Proposed antenna is designed on FR4 glass epoxy substrate with thickness $1.6 \mathrm{~mm}$ and dielectric constant 4.4. The HFSS V13 software is used to design and simulate the proposed fractal antenna. By observing the simulated results of proposed antenna it has been concluded that it works on six resonant frequency bands with the maximum value of gain $8.8 \mathrm{~dB}$ at $3.14 \mathrm{GHz}$ frequency band. The existing antenna works on maximum two frequency bands of operation. Due to the multiband characteristics of proposed antenna, it can be used for different wireless applications as per FCC standards.
\end{abstract}

\section{Keywords}

FCC, gain, return loss, HFSS, FR4.

\section{INTRODUCTION}

In wireless telecommunications related applications there is a need of multi-frequency and compact antennas. Fractal geometry is used to reduce the size of antenna [1]. Fractals are first introduced in 1975 by Benoit Mandelbort. It is a rough geometric structure that can be divided into parts, where each part is the reduced copy of the whole structure [2]. Two types of unique properties are used to design the geometries of fractal antennas. First, property is self-similarity which is used to obtain the multiband characteristics of antenna. Second, property is space-filling which is used to miniaturization of antenna [3] [4]. There are many mathematical structures that use the fractal geometries; sierpinski carpet, sierpinski gasket, meander [5], Koch, contor comb, snowflake these geometries also describes the real world objects such as mountains, clouds, coastline etc. Fractals are used for various applications such as WLAN/WSN $(2.44 \mathrm{GHz}-2.45 \mathrm{GHz})$, GSM $(0.89 \mathrm{GHz}-$ $0.96 \mathrm{GHz})$, DCS $(1.71 \mathrm{GHz}-1.88 \mathrm{GHz})$, LTE $(1.7 \mathrm{GHz}-1.9 \mathrm{GHz})$, Wi-fi/Wi-max $(2.68 \mathrm{GHz}-6.45 \mathrm{GHz})$, HIPERLAN $(5.15 \mathrm{GHz}-$ $5.25 \mathrm{GHz})$ and $\mathrm{Ku}-$ band $(8 \mathrm{GHz}-12 \mathrm{GHz})[6]$.

In this paper different types of fractal antennas such as Minkowski fractal antenna, compact multiband antenna and microstrip fractal antenna has been compared with the proposed antenna on the basis of performance parameters like return loss and gain. Detailed design and results of existing and proposed antenna is described in section 2 and section 3 .

\section{ANTENNA DESIGN}

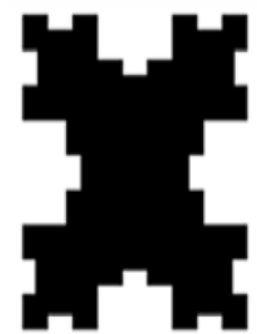

Minkowski

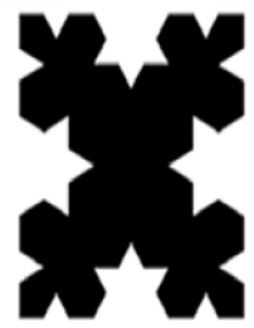

Koch

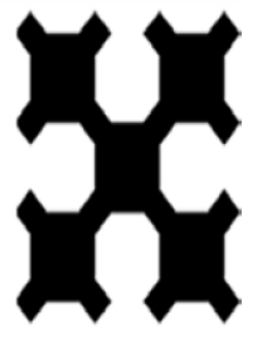

Sierpinski Curve
Figure 1: Different fractal antennas (Minkowski) [5]

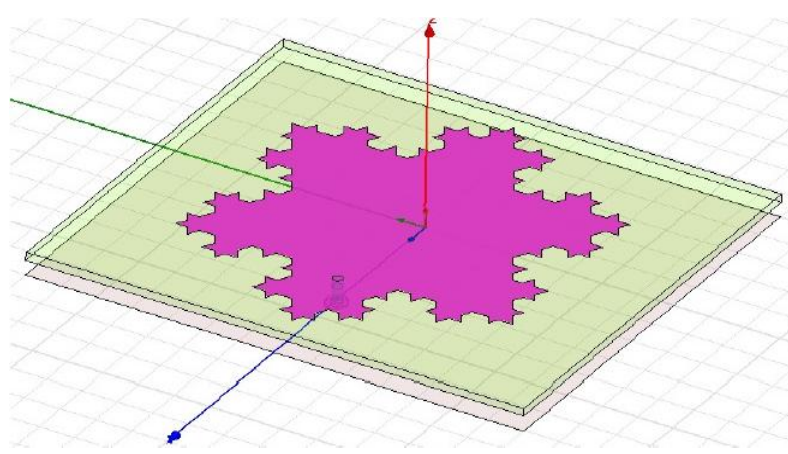

Figure 2: Compact multiband antenna [2]

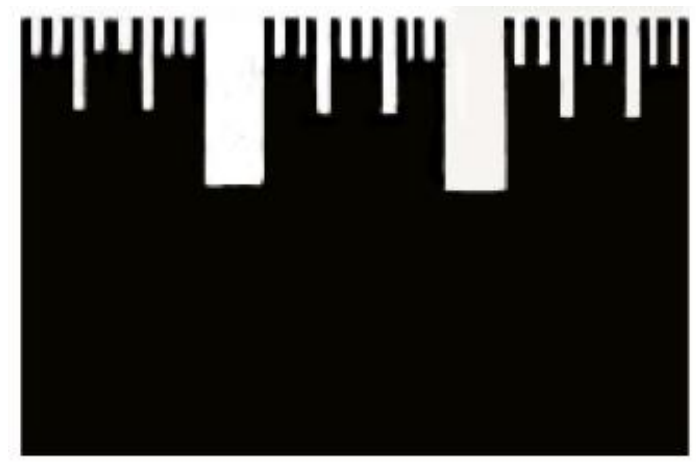

Figure 3: Microstrip fractal antenna [1]

Figure 1, Figure 2 and Figure 3 shows the design of existing antennas $[5,1,2]$. The paper on Minkowski fractal antenna describes the design of three different types of fractal antennas such as Minkowski, Koch and Sierpinski curves. All these antennas are designed on FR4 epoxy substrate. Similarly, the compact multiband and the microstrip fractal 
antennas are also designed on low cost FR4 glass epoxy substrate.

Proposed fractal antenna designed by using design equations as given below (1) to (3). In proposed antenna, the FR4 epoxy substrate with $1.6 \mathrm{~mm}$ thickness and dielectric constant 4.4 are used to design the antenna. The resonant frequency used is $3.2 \mathrm{GHz}$ and the radius of the hexagonal patch is calculated as $12.6 \mathrm{~mm}$. The proposed geometry of designed antenna is shown in Figure 4. In this design the inset line feed is used to provide the excitation to the antenna. Parametric values of proposed antenna are shown in Table 1.
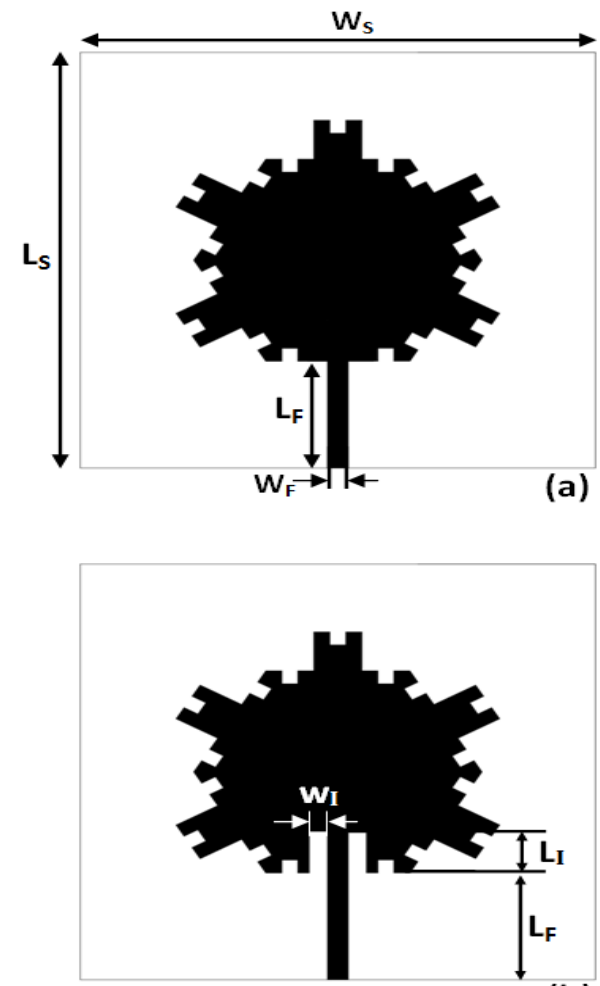

(b)

Figure 4: (a) initial geometry and (b) proposed geometry of designed antenna

$a=F\left\{1+\frac{2 h}{\pi F \varepsilon_{r}}\left[\ln \left(\frac{\pi F}{2 h}\right)+1.7726\right]\right\}^{-1 / 2}$

$F=\frac{8.791 \times 10^{9}}{f_{r} \sqrt{\varepsilon_{r}}}$

$a_{e}=a\left\{1+\frac{2 h}{\pi a \varepsilon_{r}}\left[\ln \left(\frac{\pi a}{2 h}\right)+1.7726\right]\right\}^{1 / 2}$

Where;

$\mathrm{a}=$ radius of circle

$\mathrm{a}_{\mathrm{e}}=$ effective radius of circle

$\mathrm{c}=$ velocity of light in free space

$\mathrm{f}_{\mathrm{r}}=$ resonant frequency

$\mathrm{h}=$ height of substrate

$\varepsilon_{\mathrm{r}}=$ dielectric constant of substrate
Table 1: Proposed antenna parametric values

\begin{tabular}{|c|c|c|c|}
\hline S. No. & Parameters & Description & Values \\
\hline 1. & $\mathrm{~W}_{\mathrm{S}}$ & Width of Substrate & $45 \mathrm{~mm}$ \\
\hline 2. & $\mathrm{~L}_{\mathrm{S}}$ & Length of Substrate & $44.92 \mathrm{~mm}$ \\
\hline 3. & $\mathrm{~W}_{\mathrm{F}}$ & Width of Feed & $1.8 \mathrm{~mm}$ \\
\hline 4. & $\mathrm{~L}_{\mathrm{F}}$ & Length of Feed & $11.55 \mathrm{~mm}$ \\
\hline 5. & $\mathrm{~W}_{\mathrm{I}}$ & Width of inset cut & $1.6 \mathrm{~mm}$ \\
\hline 6. & $\mathrm{~L}_{\mathrm{I}}$ & Length of inset cut & $4.5 \mathrm{~mm}$ \\
\hline
\end{tabular}

\section{RESULT AND DISCUSSIONS}

\subsection{Return loss}

The Minkowski, Koch and Sierpinski curve works on single resonant frequency bands of operation such as $6.59 \mathrm{GHz}$, $6.8 \mathrm{GHz}$ and $8 \mathrm{GHz}$ respectively. Return loss versus frequency plot of these fractal antennas is shown in Figure 5.

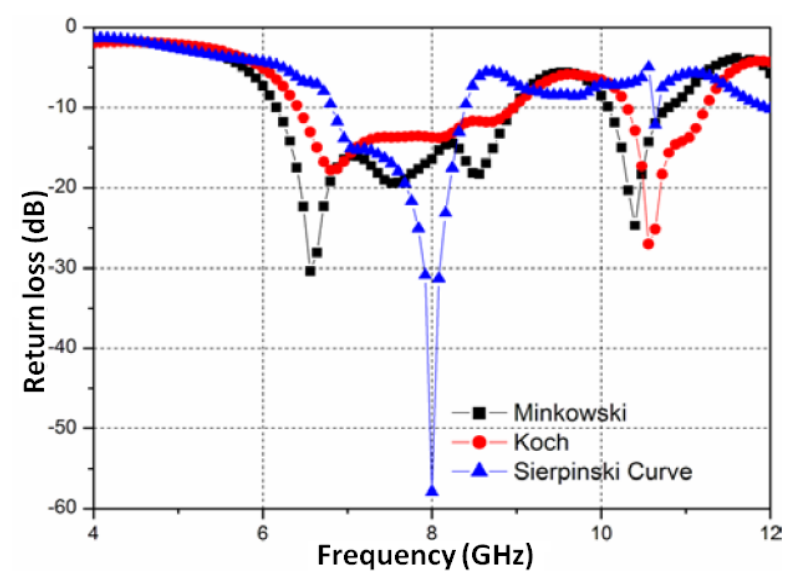

Figure 5: Return loss curve of Minkowski fractal antenna [5]

Compact multiband fractal antenna works on $2.45 \mathrm{GHz}$ frequency band with the value of return loss $-18.10 \mathrm{~dB}$. the return loss curve of compact fractal antenna is shown in Figure 6.

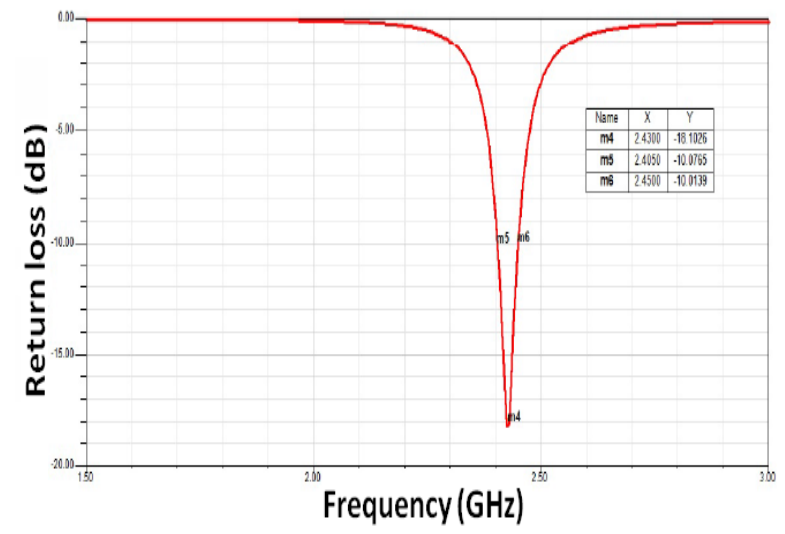

Figure 6: Return loss curve of compact fractal antenna [2]

Microstrip fractal antenna works on dual frequency bands such as $4 \mathrm{GHz}$ and $5.9 \mathrm{GHz}$ with the value of return loss as $40 \mathrm{~dB}$ and $-19 \mathrm{~dB}$ respectively. The return loss of microstrip fractal antenna is shown in Figure 7. 


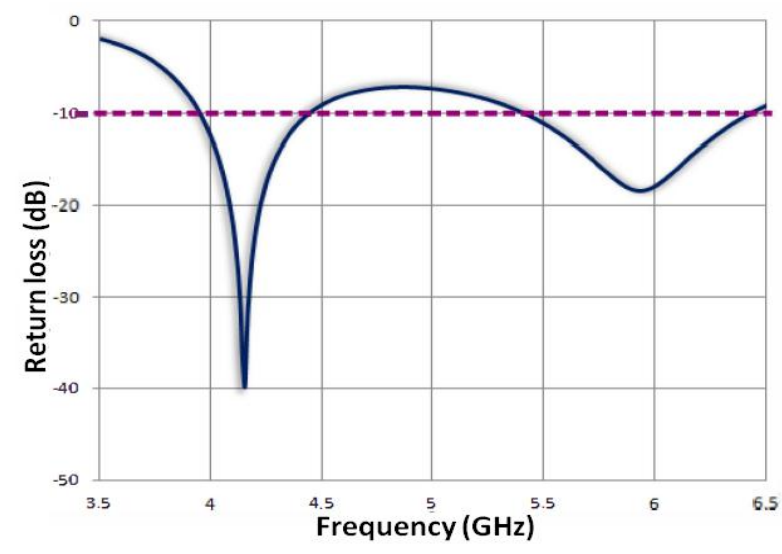

Figure 7: Return loss curve of Microstrip fractal antenna [1]

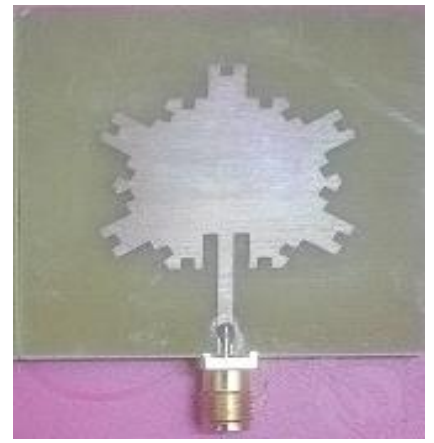

Figure 8: Fabricated structure of proposed antenna

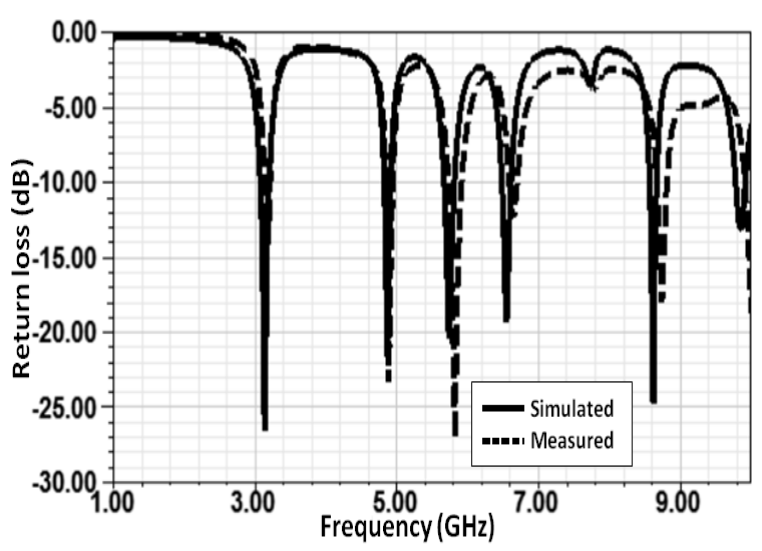

Figure 9: Return loss curve of proposed antenna

The proposed antenna is designed and then fabricated to validate the simulated results with the measured results. Fabricated structure of proposed antenna is shown in Figure 8. By comparing the simulated and measured results it has been concluded that both are in good agreement with each other. Simulated antenna works on six resonant frequencies such as $3.14 \mathrm{GHz}, \quad 4.87 \mathrm{GHz}, \quad 5.74 \mathrm{GHz}, \quad 6.55 \mathrm{GHz}, 8.62 \mathrm{GHz}$ and $9.85 \mathrm{GHz}$ with the value of return loss $-26.51 \mathrm{~dB},-21.58 \mathrm{~dB}$, $20.44 \mathrm{~dB},-19.35 \mathrm{~dB},-24.77 \mathrm{~dB}$ and $-13.41 \mathrm{~dB}$ respectively. Similarly, measured antenna works on six resonant frequencies such as $3.16 \mathrm{GHz}, 4.88 \mathrm{GHz}, 5.82 \mathrm{GHz}, 6.65 \mathrm{GHz}$, $8.74 \mathrm{GHz}$ and $10.00 \mathrm{GHz}$ with the value of return loss $13.89 \mathrm{~dB},-23.22 \mathrm{~dB},-26.96 \mathrm{~dB},-12.38 \mathrm{~dB},-17.98 \mathrm{~dB}$ and $18.69 \mathrm{~dB}$ respectively. The comparison of simulated and measured return loss of proposed antenna is shown in Figure 9.

\subsection{Gain}

The gain of existing antennas with the proposed antenna has been compared in this section. Value of gain for Minkowski fractal antenna is $4.12 \mathrm{~dB}$ at $6.59 \mathrm{GHz}$, Koch fractal antenna is $3.51 \mathrm{~dB}$ at $6.8 \mathrm{GHz}$ and Sierpinski curve is $1.05 \mathrm{~dB}$ at $8 \mathrm{GHz}$ frequency band. The compact antenna has the value of gain $5.2 \mathrm{~dB}$ at $2.43 \mathrm{GHz}$ frequency band and microstrip fractal ahs the value of gain $5 \mathrm{~dB}$ for both the frequency band as $4 \mathrm{GHz}$ and $5.9 \mathrm{GHz}$. Whereas, the proposed antenna works on six resonant frequency bands of operation with the value of gain as $8.80 \mathrm{~dB},-2.74 \mathrm{~dB}, 2.53 \mathrm{~dB}, 3.34 \mathrm{~dB}, 5.38 \mathrm{~dB}$ and $7.59 \mathrm{~dB}$ at the respective frequency band.

\section{CONCLUSIONS}

In this paper comparison has been made between the existing fractal antenna and proposed fractal antenna. By observing all the parameters it has been concluded that the proposed antenna works on more number of resonant frequency bands as compared to the existing antennas. Proposed antenna shows the multiband characteristics which is very useful for the modern wireless communication system. The proposed antenna shows the maximum gain at most of the frequency bands as compared to the existing antennas. Maximum value of gain for the proposed antenna is $8.80 \mathrm{~dB}$ at the $3.16 \mathrm{GHz}$ frequency band.

\section{REFERENCES}

[1] S. Behera and D. Barad, "A Novel Design of Microstrip fractal antenna for Wireless sensor network," IEEE, International Conference on Computation of Power, Energy, Information and Communication, 978-1-46736524-6, 2015

[2] K. Kharat, S. Dhoot and J. Vajpai, "Design of compact multiband fractal antenna for WLAN and WiMAX Applications," IEEE, International Conference on Pervasive Computing (ICPC), 2015.

[3] J. S. Sivia and S. S. Bhatia, "Design of fractal based microstrip rectangular patch antenna for multiband applications," IEEE International Advance Computing Conference (IACC), pp. 712-715, 2015.

[4] A. Kaur and N. Sharma , "A quad band circular patch antenna with fractal elements for S-band and C-band applications," International Journal of Computer Applications, Vol. 144, No. 3, pp. 1-4, 2016

[5] S. Dhar, R. Ghatak, B. Gupta and D. R. Poddar, "A Wideband Minkowski Fractal Dielectric Resonator antenna," IEEE Transaction on Antenna and Propagation, Vol. 61, No. 6, pp. 2895-2903, 2013.

[6] S. Patil and V. Rohokale, "Multiband smart fractal antenna design for coverged 5G wireless networks," IEEE, International Conference on Pervasive Computing (ICPC), 2015. 